\title{
ICD and PM Implantation Procedure: Relevant Periprocedural Issues
}

\author{
Joern Schmitt \\ Additional information is available at the end of the chapter \\ http://dx.doi.org/10.5772/54203
}

\section{Introduction}

\subsection{Perioperative management of antiplatelet and anticoagulation therapy}

Over the last years implanting physicians are frequently forced to manage perioperative situation with increased bleeding risk due to anticoagulation (oral or intravenous) or dual antiplatelet therapy. Large number of patients have indication for long term use of oral anticoagulation because of atrial fibrillation, prosthetic heart valves, anamnestic cerebrovascular accident or recurrent venous thromboembolism. On the other hand an increasing number of patients have indication for dual antiplatelet therapy (DAPT) - mainly after coronary artery interventions. There is an increased need for a standardized perioperative management by either postponing the procedure (if clinically possible), bridging or pausing the therapy or taking the risk of a bleeding complication if inevitable. To help the implanting physician with a reasonable decision, there are guidelines offered by the large cardiology societies [1-4] concerning the management of patients with $\mathrm{AF}$, as well as recent publications dealing with this increasing challenge [5-7].

\subsection{Antiplatelet therapy}

Antiplatelet therapy is usually indicated after coronary artery interventions, myocardial infarction as well as extracardial indications including cerebral infarction or peripheral artery disease. Following coronary intervention the need for dual antiplatelet therapy usually is temporally, the duration of therapy depending on the type of stent (bare metal Stent /BMS/ vs. drug eluting stent /DES/) as well as on the stent position and implant indication (acute coronary syndrome vs. elective angioplasty). Following this time period most patients will 
be put on aspirin therapy lifelong. Shortening the initially recommended time period of DAPT is highly discouraged due to high risk of stent thrombosis. On the other hand most PM and numerous ICD implants should not be postponed because of a potential or evident risk of syncope, asystoly or sudden cardiac death.

A review of recent studies shows interesting and relevant results concerning device implantations under DAPT. Patients underwent device implantation under DAPT (ASA and clopidogrel) suffered the highest rate of pocket hematomas and bleeding complications when compared to patients with ASA alone or oral anticoagulation. The risk of pocket hematoma in patients implanted under DAPT may as high as $20 \%$ in a smaller study (200 patients $10 \%$ with DAPT) [6]. Tompkins et al. retrospectively analyzed 1388 device implantations including 139 patients with DAPT, they found a 4-fold increased risk of bleeding complications compared to controls (7.2\% vs. 1.6\%) [7]. In this study patients receiving only ASA therapy had a bleeding risk more than 2 -fold $(3.9 \%$ vs. $1.6 \%)$ showing a trend to significance $(\mathrm{p}=0.078)$. Kutinsky et al. collected prospectively the data of 935 PM and ICD implantations concerning pocket hematomas. They described an overall bleeding risk of $9.5 \%$, which was significantly increased in those on clopidogrel therapy (18.3\%) [8]. Data concerning the "new" antiplatelet agents ticagrelor and prasugrel in device implantations are missing. Prasugrel showed to have a higher bleeding risk in the interventional and CABG parts of the TRITON-TIMI38 trial [9-11]. To which extend this may be extrapolated to device implantation is questionable. Ticagrelor showed a comparable bleeding risk to clopidogrel in the PLATO Trial $[12,13]$. Again there is no explicit data on the risk of bleeding and hematoma in pacemaker or ICD implant procedures.

\subsection{Oral anticoagulants}

Besides antiplatelet therapy as concomitant treatment in cardiovascular patients there are many treated with oral anticoagulants (OAC) / vitamin $\mathrm{K}$ antagonists (VKA) needing a device implantation or revision. In the last years new drugs evolved in this field of anticoagulation with broad indication spectrum reaching from deep venous thrombosis prophylaxis and therapy up to the prevention of cardio-embolic events in atrial fibrillation. In contrast to the described dual antiplatelet therapy oral anticoagulation therapy for example in AF and after mechanical heart valve replacement is a lifelong therapy with a constant risk of thromboembolic and bleeding events. Thus postponing implantation procedure - even if clinically possible - is of little help. Three options arise when dealing with patients on oral anticoagulation: 1 . Pausing OAC and bridging with unfractionated (UFH) or low molecular weight (LMWH) heparin, 2. Continue OAC and perform the implantation at a moderate INR (e.g. 1.5-2.0) if possible, 3. Pausing completely and reinitiating 3-5 days post implantation. In patients with the need for anticoagulation therapy the risk of thromboembolic events may be categorized into low, moderate or high by adopting and expanding the $\mathrm{CHA}_{2} \mathrm{DS}_{2}$-VASc-Score (table 1). The action taken should be adopted to this risk (table 2) [14]. 


\begin{tabular}{cc}
\hline Risk factor & Score \\
\hline $\begin{array}{c}\text { Congestive heart } \\
\text { failure/LV-dysfunction }\end{array}$ & 1 \\
\hline Hypertension & 1 \\
\hline Age 65-74 years & 1 \\
\hline Age $\geq 75$ years & 2 \\
\hline Diabetes mellitus & 1 \\
\hline Stroke/TIA/thrombo- \\
embolism & 2 \\
\hline Vascular disease & 1 \\
\hline Sex (female) & 1 \\
\hline Total Maximum & 9 \\
\hline
\end{tabular}

Table 1. The $\mathrm{CHA}_{2} \mathrm{DS}_{2}$-VASc-Score

\begin{tabular}{cc}
\hline Score & Risk \\
\hline 0 & 0 \\
\hline 1 & 1.3 \\
\hline 2 & 2.2 \\
\hline 3 & 3.2 \\
\hline 4 & 4.0 \\
\hline 5 & 6.7 \\
\hline 6 & 9.8 \\
\hline 7 & 9.6 \\
\hline 8 & 6.7 \\
\hline 9 & 15.2 \\
\hline
\end{tabular}

Table 2. Adjusted stroke rate according to the $\mathrm{CHA}_{2} \mathrm{DS}_{2}-\mathrm{VASc}-\mathrm{Score}$

There are several publications dealing with device implantation in anticoagulated patients. Most of them evaluate the use/benefit of perioperative bridging therapy. Giudici et al reported a series of 1025 implants including 470 oral anticoagulated patients with a mean INR of $2.6( \pm 1)$. The rate of pocket hematoma was not significantly different between the two groups (OAC 2.6\%, Controls 2.2\%) [15]. Wiegand et al. reported their analysis of predictors of pocket hematoma in $3164 \mathrm{PM} / \mathrm{ICD}$ implants and generator exchanges [16]. Besides a described risk of hematoma formation of $3.1 \%$ under ASA and $21.7 \%$ under DAPT, a higher risk of hematoma formation could be found in patients were OAC therapy was bridged with 
UFH perioperative. In this study two postoperative regiments were compared. One with a bolus of heparin immediate at the end of the procedure (2.500 IU to 5000 IU) followed by continuous infusion (target aPTT from 40-60s). The other group was started on continuous heparin infusion without a bolus within $12 \mathrm{~h}$ post implantation with the same target aPTT. The risk of pocket hematoma was $28.1 \%$ in the bolus and $12 \%$ in the standard group. One further study reports data of a "head to head" comparison in CRT-implants between patients on OAC having an INR 2-3 perioperative, a second group having heparin bridging therapy and a third - control - group including patients where OAC was simply stopped for 4 days. It showed again that the incidence of pocket hematomas were significantly increased in patients where heparin bridging was performed: $20.7 \%$ vs. $5.0 \%$ in the OAC group and $4.1 \%$ in controls $(\mathrm{p}=0.03)$. Hematomas were responsible for longer in hospital stays (controls: $1.6 \pm 1.6$; warfarin group: $2.9 \pm 2.7$; bridging $3.7 \pm 3.2$; $\mathrm{p}<0.001$ ) [17]

It should be noted that the data of all the reported studies showed different rates of hematoma formation with and without anticoagulation or bridging therapy but no significantly different rate in the occurrence of thromboembolic events were described.

Furthermore, new anticoagulant agents became available recently: the oral direct thrombininhibitor dabigatran and the oral Factor Xa inhibitor rivaroxaban, both approved to prevent thromboembolic events in patients with non valvular atrial fibrillation as well as to prevent post surgery venous thrombosis. There are only limited data on bleeding complications in pacemaker and defibrillator implantation under therapy with one of these two new approved drugs. Data from the RELY trial (dabigatran) in patients (4591 patients) with AF and the need for an interventional procedure, including pacemaker/defibrillator implantation $(10.3 \%)$ showed no significantly different risks for major bleeding when compared with warfarin (dabigatran $110 \mathrm{mg} 3.8 \%$ or dabigatran $150 \mathrm{mg} 5.1 \%$ or warfarin $4.6 \%$ ) [18]. The median dabigatran discontinuation was 49 hours (25-85) ahead of the procedure compared to 114 hours (87-144) in patients on OAC. One study was evaluating the risk of major bleeding events after total hip or total knee arthroplasty in patients concomitantly treated with NSAIDS or ASA and dabigatran (2x110mg or 1x150mg daily) [19]. In this study no difference in major bleeding events could be observed, neither between dabigatran and enoxaparin treated patients nor between concomitantly treated patients.

A recent metaanalysis by Bernard et al. [20] showed an overall incidence of bleeding complications of $4.6 \%$ ranging from $2.2 \%$ in patients without any anticoagulation/antiplatelet therapy up to $14.6 \%$ in patients receiving a heparin bridging strategy. Calculated odds ratios compared to the no therapy group was 8.3 (95\% CI 5.5-12.9) for heparin bridging strategy, 5.0 (95\% CI 3.0-8.3) for dual antiplatelet therapy and 1.6 (95\% CI 0.9-2.6) with continued oral anticoagulation. This again contributes to the idea that bridging therapy (despite high risk patients) is maybe not the best way to go.

\subsection{Conclusion / recommendation}

In our institution considering the above mentioned we decided to adopt a recommendation from Korantzopoulos et al. modified algorithm [21]. In patients undergoing generator replacement or Loop-Recorder implantation we continue the actual therapy, antiplatelet as 


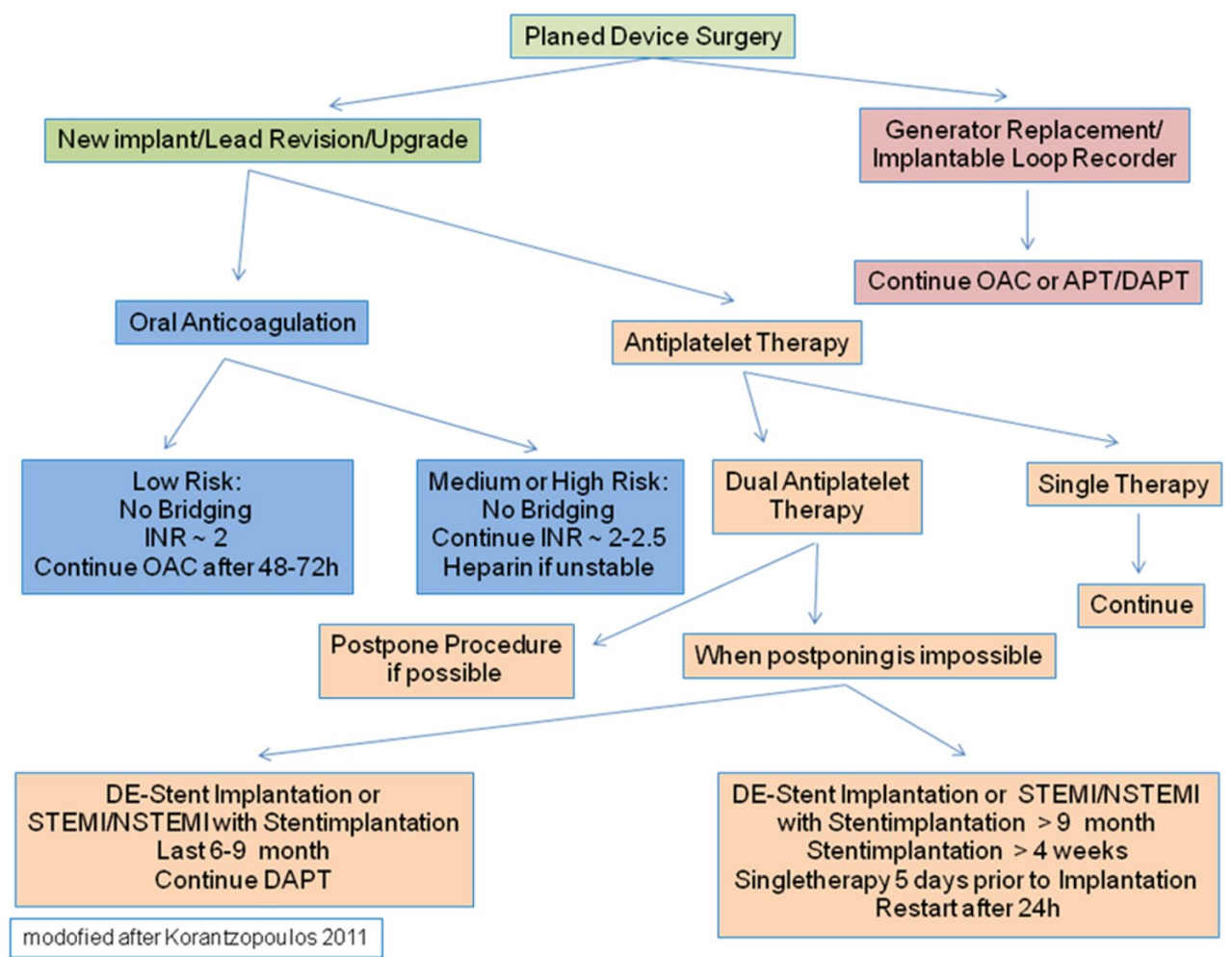

Scheme 1.

well as anticoagulation, aiming to an INR of max. 2.5. All new implantations, revisions or upgrades needing vascular access are managed differently - according to our flow chart (Scheme 1 - adopted and modified after Hofmeister and Korantzopoulos [14, 21]). If dual antiplatelet therapy is present we try to postpone the procedure, according to current guidelines depending on the indication for DAPT. The time with the need for DAPT depends on the used Stent(s) as well as the anatomic position and the indication itself (ACS vs. elective). In general DAPT is mandatory for at least 6 month, in patients after ACS as well as in patients with a drug eluting stent (DES). After non DES implantation DAPT has to be administered for at least 4 weeks. If postponing is impossible the implant-procedure would be performed under dual antiplatelet therapy and wide precautions. Single antiplatelet therapy would be continued.

In patients under oral anticoagulation therapy we apply table 1, 2 and 3 to estimate the patient's risk for thromboembolic events. Patients with low risk will be operated with a break of OAC and an INR of up to 2.0. OAC will be resumed after $48 \mathrm{~h}$ with the maintenance dose. Patients with medium risk will be operated with continued OAC and an INR of 2.0 2.5. High risk patients according to table 3 will be discussed and depending on the procedure either 
be operated with an INR close to 2.5 or heparin bridging therapy. We do not perform bridging with any type of heparin as a routine protocol. Oral Anticoagulation should be stopped approximately 3-5 days before the procedure, depending on the used substance as well the individual maintenance dose. Local haemostiptics or drainage will be used by the judgment of the operator.

\begin{tabular}{|c|c|c|}
\hline \multicolumn{3}{|c|}{ Thromboembolic risk assessment in patients on oral anticoagulation } \\
\hline Low thromboembolic risk (<5\%/year) & $\begin{array}{l}\text { Medium thromboembolic risk } \\
\text { (5-10\%/year) }\end{array}$ & $\begin{array}{c}\text { High thromboembolic risk (>10\%/ } \\
\text { year) }\end{array}$ \\
\hline $\begin{array}{l}\text { AF patients with } \mathrm{CHA}_{2} \mathrm{DS}_{2} \text {-VASc-Score } \\
\qquad 0-2 \text { (but no TIA/CVA) } \\
\text { Mechanical aortic valves (> } 3 \text { months) } \\
\text { Post venous thromboembolism (>12 } \\
\text { month) }\end{array}$ & $\begin{array}{l}\text { AF patients with } \mathrm{CHA}_{2} \mathrm{DS}_{2}-\mathrm{VASc}-\mathrm{Score} \\
\qquad 3-5 \\
\text { Mechanical aortic valves }+\mathrm{AF} \\
\text { Malignancy ass. venous } \\
\text { thromboembolism } \\
\text { Multiple or current thromboembolism } \\
\text { Valve repair/-exchange (<3months) }\end{array}$ & $\begin{array}{c}\text { AF patients with } \mathrm{CHA}_{2} \mathrm{DS}_{2} \text {-VASc-Score } \\
\text { 5-6 (or TIA/CVA }<3 \text { months) } \\
\text { Mechanical mitral valves } \\
\text { Mechanical aortic valves + AF } \\
\left(\mathrm{CHA}_{2} \mathrm{DS}_{2} \text {-VASC } \geq 2 \text { ) }\right. \\
\text { Mechanical aortic valves (older } \\
\text { models) } \\
\text { Known thrombophilic disorder } \\
\text { LV-thrombus }\end{array}$ \\
\hline
\end{tabular}

Table 3. Relative Risk assessment of perioperative thromboembolic events without anticoagulation therapy. Modified after Douketis JD, et al (2008) The perioperative management of antithrombotic therapy (ACCP Evidence-based clinical practice guidelines, 8th Edition). Chest 133:299-339 and De Caterina R, Husted S, Wallentin L et al (2007) Anticoagulants in heart disease: current status and perspectives. Eur Heart J 28:880-913

\section{Perioperative antibiotic therapy}

\subsection{Introduction}

Since the beginning of cardiac implantable electronic devices (CIED) prevention of device infection is a serious issue and is under permanent discussion [22-24].

Despite "optimal implantation procedure" concerning optimal sterility and hygienic conditions in terms of materials, implant room and process, there are several factors that pose a higher risk for CIED infections: device/pocket revision, use of temporary pacing leads before placement of the permanent device, central venous catheters, longer operative time and operator inexperience, development of postoperative pocket hematoma, diabetes mellitus, long-term use of corticosteroids and other immunosuppressive drugs and seperated focus of primary infection [25]. The use of perioperative antibiotics or the therapy of choice, as well as necessity and effect of flushing the wound with antiinfective detergents is under debate [26, 27]. There are newly developed antimicrobial device coatings which are not yet available [28, 29].

Described rates of implant related device infections in published studies have a wide range reaching from $0.13 \%$ to $19.9 \%$ with $0.5 \%$ of the patients developing endocarditis or sepsis as 
a major complication [24, 30]. In addition to the severe or even lethal complication there is also an impact on health economics with estimated costs of up to $50.000 \$$ per case [31, 32].

The daily routine of perioperative antibiotic administration to prevent infections of CIED is highly variable in terms of agents and dosage. It is generally accepted that a reduction of device infections can be achieved by this approach [33]. Regiments based on vancomycin, imipenem or cephazolin administered either perioperative as single shot or up to 3 days are known. In terms of evidence based medicine there are just 7 trials dealing with perioperative antibiotics in CIEDS up to 2009 [27, 30, 34]. They were consisted of small number of patients with very variable designs in terms of follow up duration, inclusion criteria, used antibiotic agent and definition of events. Thus varying results were reported and a definite conclusion could hardly be found. Four of those trials described a benefit in terms of reduction of device/system infections. Three did not describe any difference, however, in one study there was no infection at all in the included 106 patients [35]. Those trials were mainly conducted in the 1980's - another limitation since implanted systems (generators and leads) as well as implant techniques underwent marked developments in the last 3 decades.

The most recent and relevant study was a double-blinded randomized trial by Oliveira et al. in 2009 [36]. In this study 649 consecutive ICD and pacemaker patients (first implant and generator replacement) were included and followed (fixed schedule for 6 month and additionally when clinically indicated). Randomization was made to either $1 \mathrm{~g}$ of cephazolin or placebo directly prior operation. Allergic patients were excluded. The primary endpoint was the occurrence of infection, classified being one of the following: superficial, pocket or systemic infection. The two groups were balanced and no differences concerning the known risk factors for CIED infections were present. The study was interrupted after 26.5 month by the safety committee because of significant differences in the primary endpoint. CIED related infections occurred in $0.64 \%$ in the cephazolin group and $3.28 \%$ in the placebo group $(\mathrm{p}=0.016)$. The 13 patients that developed infections showed the typically germs all from the Staphylococcus-family. The time until infection after implantation was 11-33 days without a difference between the cephazolin and the placebo group. The multivariate analysis identified pocket hematoma and lack of antibiotic prophylaxis as independent risk factors for any kind of infection. Odds ratios were not calculated.

Based on the results of this study as well as previously published non randomized data antibiotic prophylaxis should be performed in any device related operation (implantation as well as generator replacement). In our institution cephazolin is administered - being the only evidence based antibiotic drug until now. In case of known allergy against cephazolin a single shot of $1 \mathrm{~g}$ vancomycin seems the most appropriate alternative as most common species in CIED infection are staphylococci or streptococci $[37,38]$. If the implanting hospital has a high prevalence of methicilin-resistant staphylococci (MRSA) vancomycin should be considered to be the first choice [33]. Some authors argue that in some regions with a very high prevalence of MRSA vancomycin should be even generally the first choice, however, this is not evidence based and should be considered carefully together with the local infectologist [33]. 
An interesting, newly developed approach of device coatings seems to be able to control local bacterial growth and thus is supposed to be able to prevent system infections [28, 29]. The study by Matl et al. describes the use of gentamycin and teicoplanin in a lipidbased drug delivery-system which was able to deliver high local concentrations over $96 \mathrm{~h}$ and inhibit completely the growth of S. aureaus in vivo [28]. Wong et al. published data on a dual layer device coating, consisting of gentamycin to control local colonization/ infection and diclofenac to control local inflammation due to tissue injury on top of a microbicidal base film [29]. In vitro they could show excellent results in terms of S. aureus control (figure 1). No data on extended in vivo use of any coating is yet available but the idea and techniques are promising.
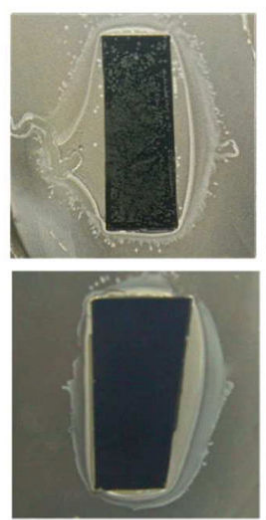

$15 \min$
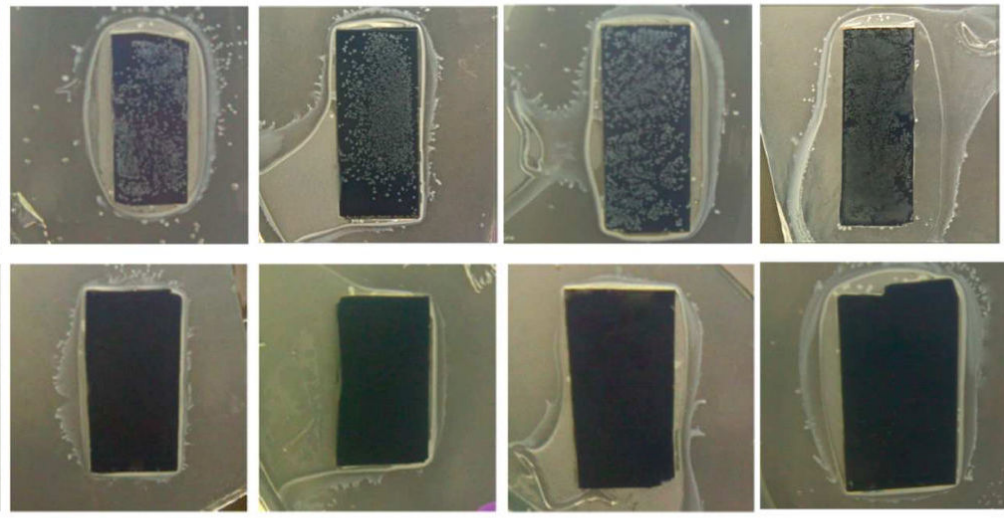

$30 \mathrm{~min}$

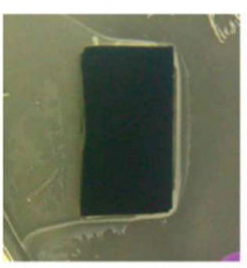

$1 \mathrm{~h}$

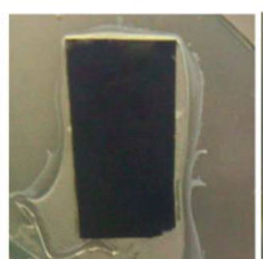

$2 \mathrm{~h}$

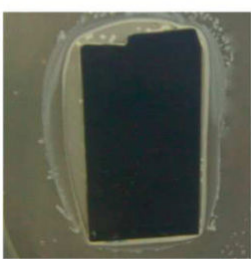

2 weeks

Figure 1. Media-borne assay with $S$. aureus with increasing time of incubation in bacterial solution; top row shows bare substrates completely colonized by bacteria (light beige colored dots); bottom row shows (DMLPEI/PAA) 10 films with degradable top films completely eroded with no sign of colonization by bacteria (black colored substrate). From Wong et al., Journal of the American Chemical Society 2010.

\section{Conclusion / recommendation}

Concerning the severe consequences arising from an infected implanted pacemaker or defibrillator and the data available there should be no discussion on the use of preventive perioperative antibiotics. Randomized data were reported only on the use of a single shot cephfazolin although some other antibiotic agents are supposed to be equally efficient as almost every perioperative device infection is caused by staphylococci or streptococci. In some hospitals with a high rate of methicillin resistant staphylococci vancomycin may be the most proper choice. There is an interesting new approach with coated devices that needs further evaluation. 


\title{
Author details
}

\author{
Joern Schmitt
}

University of Giessen and Marburg, Medical Clinic I, Department of Cardiology, Giessen, Germany and Kerckhoff Heart and Thorax Center, Department of Cardiology, Bad Nauheim,, Germany

\section{References}

[1] Fuster, V, Ryden, L. E, Cannom, D. S, Crijns, H. J, Curtis, A. B, Ellenbogen, K. A, Halperin, J. L, \& Kay, G. N. Le Huezey JY, Lowe JE et al: (2011). ACCF/AHA/HRS focused updates incorporated into the ACC/AHA/ESC 2006 guidelines for the management of patients with atrial fibrillation: a report of the American College of Cardiology Foundation/American Heart Association Task Force on practice guidelines. Circulation 2011, 123(10):e , 269-367.

[2] Camm AJ, Kirchhof P, Lip GY, Schotten U, Savelieva I, Ernst S, Van Gelder IC, AlAttar N, Hindricks G, Prendergast B et al: Guidelines for the management of atrial fibrillation: the Task Force for the Management of Atrial Fibrillation of the European Society of Cardiology (ESC). Eur Heart J 2010, 31(19):2369-2429.

[3] Lip GY, Andreotti F, Fauchier L, Huber K, Hylek E, Knight E, Lane DA, Levi M, Marin F, Palareti $\mathrm{G}$ et al: Bleeding risk assessment and management in atrial fibrillation patients: a position document from the European Heart Rhythm Association, endorsed by the European Society of Cardiology Working Group on Thrombosis. Europace 2011, 13(5):723-746.

[4] Calkins, H, Kuck, K. H, Cappato, R, Brugada, J, Camm, A. J, Chen, S. A, Crijns, H. J, \& Damiano, R. J. Jr., Davies DW, DiMarco J et al: (2012). HRS/EHRA/ECAS expert consensus statement on catheter and surgical ablation of atrial fibrillation: recommendations for patient selection, procedural techniques, patient management and follow-up, definitions, endpoints, and research trial design: a report of the Heart Rhythm Society (HRS) Task Force on Catheter and Surgical Ablation of Atrial Fibrillation. Developed in partnership with the European Heart Rhythm Association (EHRA), a registered branch of the European Society of Cardiology (ESC) and the European Cardiac Arrhythmia Society (ECAS); and in collaboration with the American College of Cardiology (ACC), American Heart Association (AHA), the Asia Pacific Heart Rhythm Society (APHRS), and the Society of Thoracic Surgeons (STS). Endorsed by the governing bodies of the American College of Cardiology Foundation, the American Heart Association, the European Cardiac Arrhythmia Society, the European Heart Rhythm Association, the Society of Thoracic Surgeons, the Asia Pacific Heart Rhythm Society, and the Heart Rhythm Society. Heart Rhythm 2012, 9(4): 632-696 e621. 
[5] Tompkins, C. Henrikson CA: Optimal strategies for the management of antiplatelet and anticoagulation medications prior to cardiac device implantation. Cardiol J (2011).

[6] Thal, S, Moukabary, T, Boyella, R, Shanmugasundaram, M, Pierce, M. K, \& Thai, H. Goldman S: The relationship between warfarin, aspirin, and clopidogrel continuation in the peri-procedural period and the incidence of hematoma formation after device implantation. Pacing Clin Electrophysiol (2010).

[7] Tompkins C, Cheng A, Dalal D, Brinker JA, Leng CT, Marine JE, Nazarian S, Spragg DD, Sinha S, Halperin H et al: Dual antiplatelet therapy and heparin "bridging" significantly increase the risk of bleeding complications after pacemaker or implantable cardioverter-defibrillator device implantation. J Am Coll Cardiol 2010, 55(21): 2376-2382.

[8] Kutinsky, I. B, Jarandilla, R, \& Jewett, M. Haines DE: Risk of hematoma complications after device implant in the clopidogrel era. Circ Arrhythm Electrophysiol (2010).

[9] Smith, P. K, Goodnough, L. T, Levy, J. H, Poston, R. S, Short, M. A, \& Weerakkody, G. J. Lenarz LA: Mortality Benefit With Prasugrel in the TRITON-TIMI 38 Coronary Artery Bypass Grafting Cohort: Risk-Adjusted Retrospective Data Analysis. J Am Coll Cardiol (2012).

[10] Wiviott SD, Braunwald E, McCabe CH, Montalescot G, Ruzyllo W, Gottlieb S, Neumann FJ, Ardissino D, De Servi S, Murphy SA et al: Prasugrel versus clopidogrel in patients with acute coronary syndromes. N Engl J Med 2007, 357(20):2001-2015.

[11] Montalescot, G, Wiviott, S. D, Braunwald, E, Murphy, S. A, Gibson, C. M, \& Mccabe, C. H. Antman EM: Prasugrel compared with clopidogrel in patients undergoing percutaneous coronary intervention for ST-elevation myocardial infarction (TRITON-TIMI 38): double-blind, randomised controlled trial. Lancet (2009).

[12] Becker RC, Bassand JP, Budaj A, Wojdyla DM, James SK, Cornel JH, French J, Held C, Horrow J, Husted S et al: Bleeding complications with the P2Y12 receptor antagonists clopidogrel and ticagrelor in the PLATelet inhibition and patient Outcomes (PLATO) trial. Eur Heart J 2011, 32(23):2933-2944.

[13] Cannon CP, Harrington RA, James S, Ardissino D, Becker RC, Emanuelsson H, Husted S, Katus H, Keltai M, Khurmi NS et al: Comparison of ticagrelor with clopidogrel in patients with a planned invasive strategy for acute coronary syndromes (PLATO): a randomised double-blind study. Lancet 2010, 375(9711):283-293.

[14] Hoffmeister, H. M, Bode, C, Darius, H, Huber, K, Rybak, K, \& Silber, S. Unterbrechung antithrombotischer Behandlung (Bridging) bei kardialen Erkrankunen. Positionspapier. Kardiologe (2010).

[15] Giudici, M. C. Barold SS: Device implantation and anticoagulation. J Interv Cardiol (2002). 
[16] Wiegand, U. K. LeJeune D, Boguschewski F, Bonnemeier H, Eberhardt F, Schunkert $\mathrm{H}$, Bode F: Pocket hematoma after pacemaker or implantable cardioverter defibrillator surgery: influence of patient morbidity, operation strategy, and perioperative antiplatelet/anticoagulation therapy. Chest (2004).

[17] Ghanbari, H, Feldman, D, Schmidt, M, Ottino, J, Machado, C, Akoum, N, \& Wall, T. S. Daccarett M: Cardiac resynchronization therapy device implantation in patients with therapeutic international normalized ratios. Pacing Clin Electrophysiol (2010).

[18] Healey JS, Eikelboom J, Douketis J, Wallentin L, Oldgren J, Yang S, Themeles E, Heidbuchle H, Avezum A, Reilly P et al: Periprocedural Bleeding and Thromboembolic Events With Dabigatran Compared With Warfarin: Results From the Randomized Evaluation of Long-Term Anticoagulation Therapy (RE-LY) Randomized Trial. Circulation 2012, 126(3):343-348.

[19] Friedman, R. J, Kurth, A, Clemens, A, Noack, H, \& Eriksson, B. I. Caprini JA: Dabigatran etexilate and concomitant use of non-steroidal anti-inflammatory drugs or acetylsalicylic acid in patients undergoing total hip and total knee arthroplasty: No increased risk of bleeding. Thromb Haemost (2012).

[20] Bernard, M. L, Shotwell, M, \& Nietert, P. J. Gold MR: Meta-analysis of bleeding complications associated with cardiac rhythm device implantation. Circ Arrhythm Electrophysiol (2012).

[21] Korantzopoulos, P, Letsas, K. P, Liu, T, Fragakis, N, \& Efremidis, M. Goudevenos JA: Anticoagulation and antiplatelet therapy in implantation of electrophysiological devices. Europace (2011).

[22] Hill PE: Complications of permanent transvenous cardiac pacing: a year review of all transvenous pacemakers inserted at one community hospital Pacing Clin Electrophysiol (1987). Pt 1):564-570.

[23] Frame, R, Brodman, R. F, Furman, S, \& Andrews, C. A. Gross JN: Surgical removal of infected transvenous pacemaker leads. Pacing Clin Electrophysiol (1993).

[24] Voigt, A, \& Shalaby, A. Saba S: Continued rise in rates of cardiovascular implantable electronic device infections in the United States: temporal trends and causative insights. Pacing Clin Electrophysiol (2010).

[25] Sohail, M. R, Uslan, D. Z, Khan, A. H, Friedman, P. A, Hayes, D. L, Wilson, W. R, Steckelberg, J. M, \& Stoner, S. M. Baddour LM: Risk factor analysis of permanent pacemaker infection. Clin Infect Dis (2007).

[26] Darouiche, R. O, \& Wall, M. J. Jr., Itani KM, Otterson MF, Webb AL, Carrick MM, Miller HJ, Awad SS, Crosby CT, Mosier MC et al: Chlorhexidine-Alcohol versus Povidone-Iodine for Surgical-Site Antisepsis. N Engl J Med (2010).

[27] Da Costa AKirkorian G, Cucherat M, Delahaye F, Chevalier P, Cerisier A, Isaaz K, Touboul P: Antibiotic prophylaxis for permanent pacemaker implantation: a metaanalysis. Circulation (1998). 
[28] Matl, F. D, Zlotnyk, J, Obermeier, A, Friess, W, Vogt, S, Buchner, H, Schnabelrauch, $\mathrm{H}$, \& Stemberger, A. Kuhn KD: New anti-infective coatings of surgical sutures based on a combination of antiseptics and fatty acids. J Biomater Sci Polym Ed (2009).

[29] Wong, S. Y, Moskowitz, J. S, Veselinovic, J, Rosario, R. A, Timachova, K, Blaisse, M. R, Fuller, R. C, \& Klibanov, A. M. Hammond PT: Dual functional polyelectrolyte multilayer coatings for implants: permanent microbicidal base with controlled release of therapeutic agents. J Am Chem Soc (2010).

[30] Bertaglia, E, Zerbo, F, Zardo, S, Barzan, D, \& Zoppo, F. Pascotto P: Antibiotic prophylaxis with a single dose of cephazolin during pacemaker implantation: incidence of long-term infective complications. Pacing Clin Electrophysiol (2006).

[31] Ferguson, T. B. Jr., Ferguson CL, Crites K, Crimmins-Reda P: The additional hospital costs generated in the management of complications of pacemaker and defibrillator implantations. J Thorac Cardiovasc Surg (1996). discussion , 751-742.

[32] Darouiche RO: Treatment of infections associated with surgical implants. (2004). N Engl J Med, .

[33] Dababneh, A. S. Sohail MR: Cardiovascular implantable electronic device infection: a stepwise approach to diagnosis and management. Cleve Clin J Med (2011).

[34] Maytin, M. Epstein LM: Proof positive: efficacy of antibiotic prophylaxis in device implantation. Circ Arrhythm Electrophysiol (2009).

[35] Bluhm, G, \& Jacobson, B. Ransjo U: Antibiotic prophylaxis in pacemaker surgery: a prospective trial with local or systemic administration of antibiotics at generator replacements. Pacing Clin Electrophysiol (1985).

[36] De Oliveira, J. C, Martinelli, M, Nishioka, S. A, Varejao, T, Uipe, D, Pedrosa, A. A, Costa, R, Avila, D, \& Danik, A. SB: Efficacy of antibiotic prophylaxis before the implantation of pacemakers and cardioverter-defibrillators: results of a large, prospective, randomized, double-blinded, placebo-controlled trial. Circ Arrhythm Electrophysiol (2009).

[37] Tarakji, K. G, Chan, E. J, Cantillon, D. J, Doonan, A. L, Hu, T, Schmitt, S, Fraser, T. G, Kim, A, \& Gordon, S. M. Wilkoff BL: Cardiac implantable electronic device infections: presentation, management, and patient outcomes. Heart Rhythm (2010).

[38] Sohail, M. R, Uslan, D. Z, Khan, A. H, Friedman, P. A, Hayes, D. L, Wilson, W. R, Steckelberg, J. M, \& Stoner, S. Baddour LM: Management and outcome of permanent pacemaker and implantable cardioverter-defibrillator infections. J Am Coll Cardiol (2007). 